\title{
EDUCAÇÃO E MODERNIZAÇÃO EM MINAS GERAIS: OS PRINCÍPIOS DA REFORMA FRANCISCO CAMPOS (1926-1930).
}

\author{
Carlos Henrique de Carvalho ${ }^{1}$ \\ Luciana Beatriz de Oliveira Bar de Carvalho
}

\begin{abstract}
RESUMO
Dentre as mudanças que marcaram a modernização do Brasil, a educação ocupou lugar central na dimensão intelectual e política do processo modernizante. Nesse sentido, este texto busca problematizar as relações entre educação e modernidade, sobretudo sua condição de índice de modernização em Minas Gerais na primeira metade do século XX. Para tanto, especulamos o discurso dos idealizadores da Reforma Educacional Francisco Campos a fim de reconhecer traços do ideário modernizante e progressista e vínculos com os interesses da elite oligárquica então predominante na política mineira. Os procedimentos metodológicos incluem pesquisa bibliográfica para contextualização conceitual e histórica, bem como leitura dos discursos de Antônio Carlos e Francisco Campos.

Palavras-chave: Francisco Campos; Reforma; Progresso; Oligarquia; Moderno.

\section{EDUCATION AND MODERNIZATION IN MINAS GENERAL PRINCIPLES OF REFORM FRANCISCO CAMPOS (1926-1930).}

\begin{abstract}
Education played a central role in the intellectual and political dimension of the process of modernization in Brazil. This text focuses on this role by discussing the relationship between education and modernity, above its condition of an index of modernization in the state of Minas Gerais in the first half of the twentieth century. To do so, we analyze governor Antônio Carlos and his secretary Francisco Campos' discourses underlying their influent education reform, which is supposed to convey traces of progress and bonds with the local oligarchy's interests. Methodological procedures included bibliographical research to contextualize conceptually and historically our discussion and analytical reading of extracts of these politicians' official discourses.
\end{abstract}

Keywords: Francisco Campos, Reform, Progress, Oligarchy, Modern.

\section{Introdução.}

Neste texto, problematizamos as relações entre educação e modernidade no Brasil tendo como ponto de problematização a educação como índice de modernização de Minas Gerais na primeira metade do século XX. Especificamente, tomamos o discurso dos idealizadores da Reforma Educacional Francisco Campos como objeto de especulação para reconhecer traços do ideário modernizante em seu conteúdo.

Para fins de contextualização histórica, retomamos alguns acontecimentos que antecederam a apresentação da reforma Francisco Campos, assim como outras reformas educacionais levadas a efeito entre as décadas de 1920 e 1930. A fim de embasar conceitualmente a problematização de artigo, discorremos brevemente sobre as noções de modernidade e modernização, tendo em vista suas implicações filosóficas, sociais, 
econômicas e políticas, sobretudo no Brasil e em Minas Gerais. Por fim, buscamos reconhecer a vinculação do ideário modernizante com a política mineira do período.

\section{Da ideia de moderno às iniciativas de modernização do Brasil republicano.}

Com efeito, mesmo o que é tido como marco concreto de modernização pode ser relativizado, isto é, volatilizado, desmanchado. Por exemplo, embora a modernização brasileira tenha um marco histórico legitimado, que indica atraso na penetração do ideário modernizante na sociedade, não é incorreto supor que o país já havia experimentado processos modernizantes no século XIX, ou seja, os processos sociais de que fala Berman. Não se pode negar que mudança de monarquia para república e o processo abolicionista não apontem para uma modernização; assim como a construção de ferrovias e portos numa economia ainda de base agrária (latifúndio, monocultura e escravismo) e o desenvolvimento da atividade mercantil interna e da atividade bancária, dentre cujo funcionamento demandava um público escolarizado. Outra mudança vista como modernizante é a vinda de europeus para substituir a mão de obra de escravos na atividade cafeeira nas fazendas. Como se vê, o país não estava de todo estanque no momento em que a modernidade se impunha na Europa.

Além de ser visivelmente tardia, poderíamos pensar, precipitadamente, que a modernização imitou as civilizações mais desenvolvidas econômica e socialmente imitação representada pela influência das vanguardas artísticas europeias. Nesse caso, seria uma modernização contraditória porque a imitação reiteraria a ideia que a sociedade brasileira ainda era primitiva. Pécaut (1990) esclarece, porém, que a assimilação não foi pacífica: o elemento estrangeiro teve de se submeter às singularidades nacionais. (Talvez por isso essa consciência dos códigos artísticos manifestada por quem articulou esse evento tenha tido tanta repercussão na produção artística nacional posterior, sobretudo na literatura.) Mesmo passível de ser vista como contraditória, diz Pécaut (1990), essa modernização estimulou o engajamento político de quem a defendeu - a problematização do cosmopolitismo e nacionalismo (mais deste) era bem-vinda ao debate político em torno de um projeto de modernização do país.

Tendo em vista esse horizonte, já as décadas iniciais do século XX, o Brasil passou por transformações políticas, econômicas e sociais decisivas para que o país entrasse na era moderna. Tais transformações se vincularam, em especial, à crise que acometeu o Estado oligárquico (crise detonada após a Primeira Grande Guerra e consolidada pelo movimento revolucionário de 1930) e da transição econômica, em que a base agrário-exportadora (cafeeira) começou a dar lugar à base industrial-urbana. Essa transição implicou uma dependência maior de países mais desenvolvidos e levou a classe agrário-latifundiária (os produtores de café) a investir noutros setores. Começava aí a constituição de outra feição para a sociedade brasileira, marcada, sobretudo, pela industrialização e que fomentou um debate denso sobre problemas sociais básicos que exigiam solução urgente, a exemplo da educação escolar.

A escolarização (primária) passou a ser objeto de uma reflexão intensa entre os intelectuais brasileiros porque, supostamente, anularia um entrave central ao progresso do país: os altos índices de analfabetismo. Mais que isso, a escola seria um instrumento valioso para disseminar o novo ideário que se impunha na sociedade (RODRIGUES, 2006). Evidentemente, a instrução escolar preocupava os dirigentes do país já na época imperial, quando a educação foi objeto de reformas. Porém, foi a partir da década de 1920 que ela se projetou com vigor, em especial porque a formação educacional foi vista como condição-chave à preparação do povo (mão de obra) para as atividades econômicas que a 
industrialização anunciava. Eis por que se diz que a década de 20 foi prolífica na política reformista da educação; assim como foi comum a projeção política dos muitos intelectuais que elaboravam as reformas levadas a efeito pelos estados, das quais algumas se tornaram relevantes, também, para a educação nacional.

O desejo de fazer o país progredir via educação e de preparar o povo para ocupar seu espaço no processo de industrialização traduzia um fenômeno mais amplo: a inserção na modernidade; isto é, em um novo ideário, em uma nova consciência de mundo, uma nova sensibilidade, uma nova percepção de realidade que mudou costumes seculares e a organização social de estilos de vida tradicionais. Seus indícios mais notáveis foram reconhecidos na Europa do século XVII, em especial na Revolução Industrial. A modernidade se difundiu no mundo como dinâmica de desenvolvimento e exaltação do presente e do futuro - diga-se, de desdém pelo passado - e se traduziu em fenômenos variados: modo de produção baseado no trabalho mecânico (produção em larga escala de bens de consumo), urbanização, outra sensibilidade estética e difusão maciça da alfabetização, para ficarmos em esferas impactadas.

\section{República e a modernização à mineira.}

A ideia de contradição se associa, também, à modernização de Minas Gerais, onde esse processo foi gradativo e multifacetado. Os entraves centrais à difusão de elementos modernizantes foram o conservadorismo e a hierarquização. Os valores da sociedade mineira exposta ao processo modernizante eram os de uma sociedade agrária (estáveis e conservadores) e de uma sociedade classista, cuja manutenção da condição de rico e de pobre legitimava e perpetuava a ordem social, além de concentrar o poder mercantil, agrícola e político nas mãos de grupos fechados ligados por parentesco (WIRTH, 1982). Arraigada à tradição, essa sociedade era composta por uma população de feição rural e tinha uma economia de base agrária voltada ao mercado interno e uma organização política ainda oligárquica. Nesse contexto socioeconômico, a assimilação dos elementos modernizadores foi desuniforme e pouco incisiva. Mais que isso, a modernização não resultou em democratização de direitos políticos, tampouco universalizou direitos tidos como universais.

Ainda segundo Wirth (1982), Minas Gerais apresentava muitos contrastes. Por exemplo, tinha relações complexas com regiões mais ricas e dinâmicas do Sul, porém mantinha vínculos fortes com regiões mais dependentes do Norte. Além de energia e recursos naturais, tinha localização geográfica, que fazia do estado uma via de passagem importante econômica e socialmente, e potencial industrial, de transporte e de renda estadual; porém, sua renda per capita era deficiente, o analfabetismo, alto e a saúde pública, precária. À força política (os mineiros dirigiram o país de 1889 a 1930 com paulistas e gaúchos) equivalia uma fraqueza socioeconômica.

Assim como é plausível reconhecer indícios de modernização já no Brasil do século XIX, Antonio Paula (2000) considera que o estado de Minas Gerais nasceu moderno. Prova disso seriam o crescimento da urbanidade (vilas) e uma estrutura de ocupação diversificada, que intensificou o comércio interno graças à mineração aurífera, à atividade manufatureira e à formação da indústria. Com efeito, segundo Paula (2000), a urbanização trouxe outro padrão de sociabilidade, novas relações políticas e econômicas, novos costumes, novas sensibilidades e novas mentalidades. As cidades viriam superar a anular feição rural da sociedade mineira como indício-chave da modernização.

No dizer de Wirth (1982), a formação das cidades mineiras principia na década de 1920, com o êxodo da população rural, atraída especialmente pela oferta de trabalho. 
Contudo, mesmo tendo cinemas, farmácias, escolas e centros de saúde pública, a maior parte das cidades pequenas mantinha vínculos fortes com a vida no meio rural, pois ainda era o produto da produção rural que mantinha a economia dessas cidades.

Se o processo de urbanização e a entrada do estado na era moderna tiveram como marco central o surgimento da capital Belo Horizonte, uma cidade planejada (WIRTH, 1982); a consolidação da vida urbana foi reforçada por outro símbolo-chave da modernização: o surgimento da indústria. Além da produção de bens de consumo e do desenvolvimento de técnicas de produção, a industrialização motivou a reorganização espacial urbana, a disciplina e o controle, a divisão do trabalho, a renda e o consumo. Mais que isso, impôs a discriminação e exclusão das classes inferiorizadas. Por isso se diz que a modernização em Minas não conseguiu suprir uma das promessas do processo de modernização: estabelecer "[...] relações econômicas capazes de produzir a melhoria das condições de vida do conjunto da população" (WIRTH, 1982, P. 81). Noutros termos, a modernização "à mineira" não enfraqueceu o tradicionalismo e conservadorismo da elite, ainda "[...] localista e isenta de crises de identificação e função [...]" (WIRTH, 1982, p. 147).

Não se pode negar, porém, que a modernização do estado que despontava na década 1920 não tenha trazido novas concepções, a exemplo das novas formas de conceber a educação, que passou a ser vista como meio de progredir. Era preciso educar as massas - diria Wirth (1982). Afinal, mesmo que a instrução pública preocupasse o governo provincial, isso não bastou para reduzir os índices de analfabetismo: "chaga" cuja extirpação supunha incluir a escola na reorganização do espaço urbano motivada pela industrialização. Dito de outro modo, era preciso reformar o sistema de instrução pública, visto que da educação do povo dependia o progresso do estado (e do país).

\section{Liberalismo e Educação na aliança Andrada-Campos}

Embora as ideias modernizantes que marcam a reforma educacional concebida por Francisco Campos e reiterada pelo então presidente de Minas Gerais Antônio Carlos nos impeçam de incluí-los nessa elite oligárquica que travou a modernização do estado, o mesmo não pode ser dito de sua condição de representantes políticos de tal elite, mesmo que isso fosse uma oposição à postura de liberalistas que os dois sugeriam ter. Segundo Peixoto (1983), o presidente de Minas afirmou a importância do voto livre e secreto, assim como reiterou seu esforço para assegurar que esse direito fosse exercido com liberdade.

Caso se possa dizer que ideologicamente a campanha política de Antônio Carlos tenha configurado uma luta pró-liberdades públicas e tradições liberais e anti-Estado analfabeto, oligárquico e autoritário (mesmo que a oligarquia compusesse sua base política essencialmente); também pode ser dito que a bandeira liberalista de campanha tenha tido fins político-eleitoreiros, isto é, foi uma tentativa angariar apoio popular citadino. Ora, com base na Tabela $1,17 \%$ da população no período enfocado aqui residia na cidade, logo defender os interesses desse povo era ignorar que $83 \%$ da população brasileira era rural. Isso relativiza a bandeira liberalista sob qual Antônio Carlos se elegera dirigente do estado. 
TABELA 1

População residente por domicílio - 1900-2000

\begin{tabular}{cccccc}
\hline \multirow{2}{*}{ ANO } & \multicolumn{5}{c}{ POPULAÇÃO EM MILHÕES } \\
\cline { 2 - 6 } & Rural & \% & Urbana & \% & Total \\
\hline 1900 & 15300000 & 90 & 1700000 & 10 & 17000000 \\
1920 & 27500000 & 83 & 4600000 & 17 & 32100000 \\
1940 & 28300000 & 68,1 & 12900000 & 31,3 & 41200000 \\
1950 & 33200000 & 63,8 & 18800000 & 36,2 & 52000000 \\
1960 & 38800000 & 55,5 & 31300000 & 44,5 & 70100000 \\
1970 & 41100000 & 44,1 & 52100000 & 55,9 & 93200000 \\
1980 & 38600000 & 32,5 & 80400000 & 67,5 & 119000000 \\
1991 & 35800000 & 24,5 & 111000000 & 75,5 & 146800000 \\
2000 & 31800000 & 18,7 & 138000000 & 81,3 & 169800000 \\
\hline
\end{tabular}

Fonte: INSTITUTO BRASILEIRO DE GEORGRAFIA E ESTATISTICA/IBGE, 2002.

Além disso, ser liberalista era assumir uma um ideário de definição imprecisa, arriscada, diria Bobbio (1991), para quem os grupos e partidos de inspiração liberal não se assumiram como liberais e partidos liberais não seguiram os princípios nem agiram politicamente à luz dessa doutrina. Por isso, convém entender a definição de liberalismo numa perspectiva múltipla, como forma de pensamento heterogêneo, multitendencioso, ajustável aos espaços e tempos históricos.

No dizer de Bobbio (1991, o liberalismo pode ser entendido como filosofia política da época moderna; doutrina gestada na Inglaterra ao longo do século XVII, cuja formulação precisa surgiu no Segundo Tratado do Governo civil, de John Locke (16321704). Paim (1984, p. 81) reitera esse conceito nestes termos:

Incorporadas ao Bill of Rights (1689), as teses lockeanas enriqueceram-se pela prática parlamentar inglesa, durante o século XVIII, do mesmo modo que pela teoria do liberalismo econômico de Adam Smith (1723-1790). Justamente esse conjunto de doutrinas é que se tem em vista quando se associa o liberalismo à sociedade industrial do tipo capitalista. Convém precisar, finalmente, que o liberalismo assim concebido - e que se caracterizará de forma apropriada logo adiante - evolui para incorporar a idéia democrática, notadamente a partir da segunda metade do século XIX, sem que o processo requeresse maiores alterações no arcabouço básico mas apenas a ampliação do conceito de representação. Esta, na versão original, aplicava-se apenas à elite dirigente, proprietária.

Se algumas das raízes do liberalismo remontem ao humanismo (como a contestação da autoridade da Igreja), os movimentos tidos como liberais surgem à época do Iluminismo (a exemplo da oposição à monarquia absoluta e ao mercantilismo). Para Weffort (2006), a teoria política de Locke no Segundo Tratado seria a primeira e mais completa formulação do Estado liberal, pois está em sua filosofia a defesa dos direitos naturais inalienáveis do indivíduo (à vida, à liberdade e à propriedade). Para Locke — diz Weffort (2006) —, antes que a sociedade e o Estado surgissem, o homem vivia no estado de natureza - estágio présocial e pré-político - em que gozava de liberdade e igualdade e era dotado de razão.

A história do liberalismo como ideologia hegemônica aponta como princípio a necessidade de o governo preservar a liberdade individual - liberdade como algo fundamental aos direitos políticos e ao Estado. Em linhas gerais, o liberalismo se associa ao direito de discordar da autoridade política e religiosa e rejeitar fundamentos de sistemas passados de governo político, a exemplo do reinado como algo divino e da hereditariedade; de usar o voto para escolher governantes; de ter igualdade perante a lei e de que todos tenham direitos iguais baseados em leis e que não infrinjam a liberdade do outro; assim como direitos individuais e civis (à vida, à liberdade e à propriedade). Subjacente a essas 
ideias, está o princípio de que o homem nasce livre e a sociedade tem de proporcionar meios para que ele aja livre e conscientemente.

No Brasil, o ideário do estado liberal penetrou, segundo Paim (1998), na voz de intelectuais que foram estudar em países europeus e nos Estados Unidos. Proclamada a República no país, a doutrina liberalista se consolidou, graças à intelectualidade, que a incorporou em sua discussão sobre mudanças. Esse autor afirma que um defensor convicto dos ideais liberalistas na Primeira República foi Rui Barbosa, cujas campanhas presidenciais de 1910 e 1919 apresentaram plataformas permeadas pelo pensamento liberal numa tentativa de estruturar o liberalismo como orientação da opinião nacional.

Segundo Machado (2009), as características tidas como liberais em Rui Barbosa incluíam sua divulgação do projeto de modernização e seu envolvimento na mudança do trabalho escravo para o livre, da monarquia para o republicanismo e da economia agrária para uma industrial. Ainda segundo esse autor, modernizar para Rui Barbosa significava, sobretudo, educar o povo com um sistema nacional de educação e uma reforma do sistema de ensino de então, recomendados em seus pareceres "Reforma do ensino secundário e superior", de 1882, e "Reforma do ensino primário e várias instituições complementares da instrução pública", de 1883. A educação escolar seria, então, a força do desenvolvimento nacional.

Embora Rui Barbosa atribuísse à educação o papel de fator de desenvolvimento, progresso e liberdade. Por outro lado, pode-se afirmar que progredir ia além da criação de condições materiais, pois significava manter a ordem necessária à sociedade burguesa. Assim, os traços liberais em Rui Barbosa não anulam em sua obra a força do espírito de uma época de uma sociedade que aspirava à modernização, porém mantendo a estratificação social. Daí se deduz um liberalismo ineficaz.

Segundo Paim (1998), o liberalismo foi mais fértil na década de 1920, quando muitos movimentos contestatórios surgiram, o capitalismo deu sinais de expansão e a sociedade civil foi instada a participar mais da vida pública mediante o voto. Todavia, a Constituição de 1891 restringiu o direito ao voto; ${ }^{3}$ e essa restrição — sobretudo ao voto popular - indica um liberalismo conservador e contraditório: a defesa de tom liberalista por uma participação maior da sociedade civil na vida pública ignorava que a maioria expressiva da população estava legalmente alijada do direito de votar.

No dizer de Pinheiro (1997, p. 32),

\begin{abstract}
A instituição da democracia representativa e do sufrágio universal masculino, avanços aparentes em relação ao quadro político anterior, eram símbolos poderosos que tinha condições de legitimar a dominação das classes dominantes tradicionais. As restrições do voto ao analfabeto, contidas na constituição de 1891 excluindo do sistema representativo os trabalhadores rurais e quase a totalidade do operariado urbano eram consideradas menos discriminatórias que o voto censitário, baseado na renda, porque fundadas em noção como "cultura", "educação", ligadas à ascensão da burguesia.
\end{abstract}

Se o liberalismo se comprometia fundamentalmente com a consolidação e o desenvolvimento de instituições do sistema representativo e o direito ao voto, democratizar o sufrágio, segundo Paim (2000), tornou-se um desafio enorme para doutrina liberal no século XX; afinal, em seus primórdios esta não se comprometia com o ideal de democracia. Seu propósito era frear e limitar o poder absoluto do monarca. Nessa ótica, a democratização via sufrágio distorceu o ideário liberalista. Para Paim (2000, p. 132), os liberais de países como o Brasil "[...] são instados a reconhecer que as tradições culturais predominantes lhes são desfavoráveis. Sem enfrentar essa questão, dificilmente serão 
capazes de formular políticas mobilizadoras, aptas a contribuir para a consolidação e a subseqüente hegemonia das tradições liberais".

Com efeito, as classes dominantes na Primeira República, afirma Pinheiro (1997), tinham gostos e opiniões conservadoras, além de serem arraigadas ao status quo. Estrategicamente, diziam querer a democracia, mas reproduziam a exclusão política do império. O governo mineiro de Antônio Carlos e Francisco Campos não foi exceção, pois sua política de feição liberal - que defendia o direito de voto a todos - excluía muitos cidadãos. Paim (2000, p. 114) explica isso assim: a representação política liberal, em geral, afirmava que, numa democracia, os cidadãos agem “"...] principalmente para maximizar o seu interesse pessoal e sua renda. Os partidos políticos, por sua vez, formulam políticas para ganhar eleições e não o inverso, isto é, não ganham eleições para formular políticas". Em outras palavras, o partido político deve catalisar interesses e reprimir intenções particulares que visassem uma sobreposição ao interesse geral.

Ainda seguindo a ótica liberalista, Antônio Carlos e Francisco Campos queriam disseminar a educação primária pública, gratuita e de qualidade a toda a população de Minas. Conforme Paim (2000, p. 146), os educadores liberais tiveram papel central na assimilação do consenso de que a educação obrigatória (fundamental ou básico) seria capaz de "[...] elevar os padrões de renda e eliminar a pobreza [...] à medida que o sistema representativo ganhou dimensão universal". Se assim o for, então convém entender um pouco das relações entre liberalismo e processo pedagógico nos anos 1920, sobretudo com a difusão do movimento da escola nova, importante para constituir o pensamento liberal no mundo e fundar teoricamente a educação para a cidadania. A educação liberal é

[...] em primeiro lugar, a herdeira do sistema de ensino criado na Época Moderna pelas igrejas protestantes e que, no século passado, tornara-se uma incumbência das comunidades, conhecido pela denominação de educação popular. Essa transição das escolas confessionais para o sistema público deu lugar a um grande embate - de natureza teórica, mas envolvendo também encarniçada luta política - , que determinou pelo estabelecimento de uma legislação fixando o caráter do ensino oficial, de maneira que não interferisse na liberdade religiosa. Somente em nosso século este sistema de ensino foi batizado de forma adequada. Chamou-se de educação para a cidadania. (PAIM, 2000, p. 137).

A influência do liberalismo na educação do Brasil veio, em especial, de Dewey, isto é, da escola nova, que pretendia — diz Paim (1998) - levar a proposta liberal ao plano curricular-pedagógico e, assim, fazer surgir uma educação para a cidadania. Também Nagle (2001, p. 310) afirma que não havia indícios claros de um movimento liberal; este ganharia contornos nítidos em meados dos anos 1920, quando o escolanovismo no país diz esse autor - entra na fase da difusão de seu ideário.

Nesta fase se encontra a difusão sistemática dos ideais da Escola Nova, período em que a literatura educacional, além de se expandir, se altera qualitativamente, dada a frequiência com que se publicam trabalhos sobre assuntos referentes à "nova pedagogia". Ao mesmo tempo se difundem as novas idéias e aparece a nova literatura, se processa a infiltração do escolanovismo no movimento reformista da instrução pública: na década de 1920 tenta-se, pela primeira vez, realizar o novo modo de estruturação das instituições escolares. (NAGLE, 2001, p. 310).

Como produto da década de 1920 e da lavra de dois políticos de extração liberal, a reforma Francisco Campos não podia fugir a esse ideário. Isso fica patente na proposta de mudança que coerente com a efervescência ideológica e a inquietação social ante um 
descompasso entre forças sociais dominantes (a oligarquia) e forças sociais emergentes (a modernização). Se for correto que o programa de governo de Antônio Carlos e Francisco Campos buscava suprir demandas sociais como a educação para todos seguindo a bandeira liberal; também é correto dizer que essa deixava entrever contradição, sobretudo se considerarmos que Campos virou Ministro da Justiça, de Estado (o Novo) contrário às ideias liberalistas defendidas por ele quando estava envolvido com o governo mineiro. Mais que isso, essa contradição possibilita aventar a ideia de que as demandas que tentaram não eram aquelas das forças emergentes, mas das forças conservadoras: as elites mineiras.

O quadro político brasileiro, sobretudo em Minas Gerais, tinha uma feição complexa porque traduzia a vontade das oligarquias estaduais conservar privilégios lançando mão de estratégias políticas espúrias. Tais estratégias ganhavam forma na mão de políticos que, não raro, provinham da classe oligárquica e que compunham a "elite" intelectual do país. A presença de Campos no governo Antônio Carlos como político e intelectual pode ser tomada como exemplo da presença oligárquica numa proposta liberal de governo e de educação. Subjacente a essa presença estava o pressuposto de que, diria Pécaut, ${ }^{4}$ os intelectuais brasileiros, supostamente quem detinha o conhecimento, estavam aptos a solucionar problemas sociais graves como o analfabetismo e a suposta ignorância do povo. Entregaram-se à ação política como se tivessem qualificação e preparo especial para fazê-lo. Muitos se tornaram protagonistas políticos centrais, como Francisco Campos.

Uma vez na elite dirigente, acreditavam que viam a "realidade brasileira" como ninguém: conheciam os mecanismos sociais e os interesses profundos de grupos distintos, dão se posicionavam como mediadores indispensáveis às classes. Ainda segundo Pécaut, com o processo de decadência do Estado oligárquico, os intelectuais, originários de famílias dessa estirpe, buscaram se projetar na política ante o temor de perder o status e o estilo de vida das elites ditas cultas. A política era a oportunidade de terem uma ocupação profissional que lhes daria visibilidade pública e preservaria sua posição nas elites dirigentes. Essa estratégia marcou o período posterior à passagem do Império para a República, quando gerações sucessivas de políticos-intelectuais e intelectuais-políticos abraçaram as causas do povo em prol de um "projeto nacional" e invocaram a "realidade nacional", diria Pécaut, em prol da construção de outra sociedade.

Todavia, diz Pécaut (1990), tal engajamento soava falso. Ora, como burgueses de origem, os intelectuais-políticos não se desvinculavam de seus interesses específicos nem agiam para "[...] fazer prevalecer valores de justiça. Apenas o faziam porque o intelectual tinha de estar à altura da construção da nação, portador que era da identidade nacional e, além disso, detentor do saber relativo às leis da evolução histórica" (PÉCAUT, 1990, p. 6). Para esse, os intelectuais justificavam sua presença na política porque o povo era ignorante e classes sociais se formavam; dada a ignorância do povo, seria fácil lhe incutir ideologias; enfim, a ideologia permitia que fossem da elite quando necessário e do povo quando conviesse.

Antônio Carlos e Francisco Campos não estavam alheios a esse contexto; para eles, a educação do povo era uma forma de suprir as demandas sociais e contribuir para a construção do "projeto nacional". Nessa lógica, na defesa da reforma da educação em Minas Gerais, Campos se mostrou na posição de intelectual afeito à constituição do país via reforma educacional. Como diz Pécaut (1990), os projetos intelectuais de então, sobretudo os da educação, não se separavam do desejo de mudar a esfera cultural e política: tudo estava em jogo ao mesmo tempo (PÉCAUT, 1990). Se assim o for, que interesses políticos tinham Antônio Carlos e Francisco Campos? Convergiam para o contexto imediato ou para o contexto mais geral, futuro? Cumpriam exigências mais 
profundas que não as do calor do momento? Vejamos se há elementos que respondam a essas indagações nas propostas políticas educacionais para Minas Gerais.

\section{Educar para modernizar: a Reforma Francisco Campos.}

Com efeito, reformas da educação estiveram na pauta da política educacional mineira nas primeiras décadas do século passado: em 1906 (João Pinheiro), ${ }^{5}$ em 1910 (Wenceslau Brás), ${ }^{6}$ em 1910-1 (Bueno Brandão), ${ }^{7}$ em 1915-6 (Delfin Moreira), ${ }^{8}$ em 1924-6 (Mello Viana), ${ }^{9}$ além das modificações educacionais feitas durante o governo Artur Bernardes (1921-4). ${ }^{10}$ Essas iniciativas reformistas antecederam a reforma que se tornaria a mais importante: a Reforma Educacional Francisco Campos, levada a efeito pelo governador Antônio Carlos Ribeiro de Andrada ${ }^{11}$ e seu secretário de Interior, Francisco Luís da Silva Campos. ${ }^{12}$ Mais ampla que a reforma de 1925, a Francisco Campos foi anunciada numa circunstância pomposa: a festa cívica do primeiro Centenário do Ensino Primário, da qual participaram seis mil pessoas, dentre as quais crianças cantando o hino, desfile e lançamento de edição especial da Revista de Ensino, órgão oficial da diretoria de Instrução Pública (VIDAL, 2009).

Segundo Peixoto (1983), a reforma de Campos se preocupou com a face técnicopedagógica da escola, assim como com uma renovação escolar coerente, diria Abreu (2001, p. 999), com os “[...] postulados da 'escola nova ${ }^{13, ", ~ e n t a ̃ o ~ d i f u n d i d o s ~ n o ~ p a i ́ s ~ n a ~}$ voz de educadores como "[...] Anísio Teixeira e Fernando de Azevedo"[...] no pósPrimeira Guerra Mundial.

Como reiteramos até aqui, se modernizar significava, então, romper com a tradição do passado, podemos supor que os postulados da escola representavam a modernização, pois propuseram uma quebra da tradição no ensino, isto é, do que Campos - segundo Abreu (2001, p. 999) - via como retórico e ornamental, próprio para formar elites; logo a escola nova, supostamente, opunha-se a isso, uma vez que "[...] deveria ensinar a pensar, a inventar e a criar soluções para a multiplicidade de novos problemas da complexa vida moderna". Para Campos, ainda segundo esse autor, a orientação e o incremento da instrução primária não poderiam “[...] fazer eleitores" se não os tivessem "[...] feito cidadãos" antes, mediante uma educação que formasse homens e orientasse a inteligência. Para Campos - diz Medeiros —, o futuro das instituições democráticas dependia dessa formação. Dito de outro modo, a "escola nova" poderia embasar a formação de cidadãos aptos a participar da sociedade moderna pelo voto (a democracia como participação de todos). Como quer Nagle (2001), a escola seria ajudaria fundamentalmente a consolidar a sociedade moderna democrática e modernizar o estado de Minas.

Se essa reforma compunha o processo modernizador de Minas Gerais, estaria ela isenta de contradições? O discurso pró-modernização de Campos não replicava as contradições desse processo em Minas? Teria ele esbarrado na estrutura oligárquica, digase, conservadora e arcaica, de Minas Gerais? Vejamos como se apresenta o discurso do Francisco Campos secretário dos Negócios do Interior de Minas Gerais; cremos que aí seja possível reconhecer ideais de moderno e modernização relacionáveis com a proposta educacional patente na reforma da educação que ele elaborou.

O livro Pela civilização mineira (1930) reúne discursos de Campos publicados em documentos da Secretaria dos Negócios do Interior que, talvez, permitam encontrar uma via de compreensão e interpretação da reforma de ensino elaborada por ele e levada a efeito no governo de Antônio Carlos. Consideremos o trecho a seguir, que compõe o documento "Exposição de motivos do Novo Regulamento do Ensino Primário - 14 de 
outubro de 1927" e dá pistas da visão geral que Campos tinha de educação escolar e da ser educada:

Si a escola, porém, pela educação, adapta a creança á vida social, fazendo-a assimilar a ordem intellectual e moral reinante, de que é um poderoso instrumento de conservação, ella, por sua vez, como órgão de aspirações e de ideaes, reage sobre a sociedade, a cujo serviço é destinada, introduzindo-lhe na circulação fermentos e reactivos que lhe provocam alterações e transformações profundas, agindo, quer immediatamente, por influencia directa, quer mediata e indirectamente, por intermédio dos futuros cidadãos, cuja intelligencia e cujo caracter receberam a marca da sua influencia, indelével por que impressa em metal ainda em via de resfriamento e de condensação e, por conseguinte, plástico e ceroso. (CAMPOS, 1930, p. 13).

As palavras de Campos sugerem que a educação escolar reflete aspirações de cada época e sociedade, conserva a ordem (intelectual e moral) vigente e visa "adaptar" a criança à vida social. Adaptar, nesse caso, sugere moldá-la à vida em sociedade, daí a comparação metafórica com a ideia de metal quente, isto é, pronto para ganhar formas mediante a manipulação esmerada, disciplinada e rigorosa do metalúrgico (do professor).

O documento cita várias outras questões sugestivas de um ideal modernizador no discurso de Campos, dentre as quais estão estas: garantir cooperação entre escola e meio social; fazer valer a condição da escola como miniatura da sociedade; apontar a educação primária como algo que não prepara para a vida escolar; entender mais o desenvolvimento físico e psíquico da criança mediante a psicologia e biologia; recorrer a orientações e pensamentos novos acerca do processo de ensino e aprendizagem, afinal "[...] quem não está aberto a inovações [à modernização] é retrogrado"; introduzir o método Decroly (centros de interesse); qualificar os programas de ensino e a formação docente reformando o ensino normal; inspecionar a parte técnica da educação; oferecer assistência escolar médica e odontológica; organizar o conselho superior de educação e o magistério em carreira regular; enfim, aparelhar e construir prédios escolares. Com efeito, o documento é abrangente, o que permite cogitar que, para Campos, melhorar a educação era fator central ao desenvolvimento (à modernização) de Minas Gerais.

Uma ideia central no discurso de Campos foi a de que qualificar a escola normal diga-se, prover formação docente pedagógica especializada - era premente para qualificar a escola primária. $\mathrm{Na}$ "Exposição de motivos do Regulamento do Ensino Normal - 20 de janeiro de 1928", ele advoga o papel central do professor e da presença de técnicos e psicólogos no ensino normal, assim como da biologia, higiene e psicologia educacional. $\mathrm{O}$ "Discurso de installação do curso de aperfeiçoamento - 14 de junho de 1928", que trata do aperfeiçoamento docente, reforçou o conteúdo da "Exposição... de 1928". Acrescentese que esses dois documentos revelam uma aspiração à reforma do espírito, dos processos e da organização do ensino primário. Contudo, mais que renovar e readaptar a escola normal era preciso rever:

[...] as exigências e a finalidade do ensino primário, os seus methodos, os seus processos e os seus programmas; uma larga e fecunda actividade prática e theorica tem-se exercido, infatigavelmente, na investigação dos seus termos, dos seus fins e dos coefficientes intellectuaes e moraes de sua organização; experiências, tentativas, reformas e projectos multiplicam-se, dia a dia, no sentido de approxima-lo cada vez mais das finalidades e exigências que lhe estão, visivelmente, a impor não apenas o estado actual, senão as formas virtuaes que tendem a revestir e definir a nossa cultura e, 
por conseguinte, a nossa concepção dos valores humanos. (CAMPOS, 1930, p. 41).

Como se pode ler nessa passagem, renovar a educação se ajustava a necessidades maiores: aquelas da sociedade moderna. Eis por que a reforma tinha de ser profunda, mediante experiências, projetos e atividades práticas e teóricas que redundassem em métodos e técnicas para qualificar a educação; isto é, suprir os interesses da sociedade que se formava - diria Carvalho (1998, p. 169): uma adequação de populações urbanas resistentes à ordem da modernidade, "[...] adequação dos costumes urbanos às exigências do trabalho industrial na ordem capitalista", na qual a escolarização poderia ser alternativa ao controle pela violência policial (CARVALHO, 1998, p. 169).

Esse aprofundamento fica patente na defesa da presença das cadeiras de biologia e psicologia educacional. Supostamente, essas áreas poderiam proporcionar um conhecimento maior da fisiologia e da intelecção da criança; mais que isso, traduziam uma "pedagogia moderna" em que

\begin{abstract}
A "ciência suprema do mestre" residia no "conhecimento do discípulo" no método tradicional", os alunos se dobravam a "rígidas prescrições gerais"; no "método moderno", o ensinamento é que se adaptava "ao discípulo como centro do mundo escolar". Tal adaptação deveria alicerçar-se em "estudo profundos sobre a evolução física, moral e intelectual da criança, nos quais a "pedagogia experimental' vinha-se "firmando brilhantemente" [...] A "psicologia moderna" fornecia as "regras diretoras da escola nova: fazer agir a criança; ocupá-la em trabalhos cuja utilidade ela sinta; despertar o interesse a fixar a atenção, partindo sempre do conhecido para o desconhecido, do fácil para o difícil, encadeando observações ate a descoberta de um principio e a verificação ulterior das aplicações desse principio inconscientemente já feitas". (CARVALHO, 1998, p. 228).
\end{abstract}

A defesa de Campos da recorrência a áreas da ciência que pudessem dar aporte à educação se fundava no que ele via como uma organização a poderosa: a indústria. Para ele, o conhecimento da organização racional do trabalho e da organização de técnicas industriais havia surgido da rotina, das práticas, dos hábitos, da repetição de processos industriais. Nesse caso, a escola como espaço de assimilação da moral, do saber e dos costumes vigentes supunha uma disciplina do corpo e do espírito dos alunos que pudessem torná-los compatíveis com o universo fabril.

Com efeito, o "Discurso de agradecimento, no banquete oferecido pelas classes intellectuaes de Bello Horizonte — 22 de outubro de 1926" mostra o quanto Campos estava alinhado ao processo de industrialização do país. Para ele, o desenvolvimento (a modernização) se vinculava à organização econômica, industrial e comercial, que garantiria a atividade social e política do país. A passagem a seguir ilustra essa afirmação:

Um paiz sem organização industrial e comercial, com toda a sua majestade, as suas dragonas, os seus parlamentos, as suas declarações de direitos, não passará de um embryão nacional, com uma vida de relação inteiramente artificial e inconsistente por insufficiencia dos seus órgão de nutrição. Até aqui temos cuidado mais de nossa vida de relação do que da nossa vida de nutrição. Começamos a nos apparelhar agora para as duras competições próprias do cyclo de civilização e de cultura dos nossos dias, dirigindo a nossa attenção para os difficeis problemas de organização econômica, industrial e commercial - de maneira a garantir ao mercado nacional as condições indispensáveis á sua efficiencia como órgão destinado a manter e assegurar a nossa actividade social e política, ate agora desapercebidas de uma base physica proporcional á grandeza e extensão do nosso aparelho 
político. [...] Ora, nós não podemos enriquecer como nação, si o nosso commercio não se acha sufficientemente apparelhado para exercer a sua funcção de colletor e distribuidor, da maneira mais remuneradora possível, das riquezas e da producção do paiz. (CAMPOS, 1930, p. 87).

Essa crença na industrialização como modelo para a reformulação da educação escolar se mostrava ainda na renovação da técnica pedagógica com base no conhecimento derivado da rotina e nas práticas da fábrica. Assim, testes de inteligência, graduação e classificação dos discentes, diferenciação dos indivíduos, pedagogia de Dewey e outros elementos compunham a fundamentação da reforma da educação. Era preciso modificar a prática da escola, seus processos, seu mecanismo, seus hábitos para adaptá-la às necessidades do mundo contemporâneo: científicas, de produção, profissionais e culturais. $\mathrm{O}$ argumento de Campos pró-renovação educacional se apoiava na ideia de que a escola que propunha era a escola dedos países mais avançados no processo de industrialização (modernização): países europeus como Alemanha, Inglaterra, Bélgica, além dos Estados Unidos. Assim, se a incorporação dos "[...] benefícios da civilização" — concepções e métodos educacionais de fora - ajudaria a escola a cumprir seu papel de partícipe do desenvolvimento do país, também seria um modo de disciplinar a "[...] densa e compacta massa de analphabetos" para transformá-lo em "[...] instrumentos de producção de bens econômicos e espirituaes [...]", sujeitos ao controle e à disciplina próprios do espaço de produção industrial; isso era exigência urgente "[...] da nossa vocação democrática [...]" (CAMPOS, 1930, p. 71).

Essa campanha em prol da melhoria da educação escolar, de uma reforma profunda, de uma renovação de concepções, modelos e modelos métodos para a escola continha intenções politiqueiras, como se pode ler nesta passagem de seu "Discurso de instalação do Congresso de Instrução — 8 de maio de 1927”:

O futuro das instituições democráticas depende, sobretudo, da orientação e do incremento do ensino primário. [...] Não basta, pois, difundir o ensino primário para dilatar os limites da cidade. Si este ensino não forma homens, não orienta a intelligencia e não distila o senso commum, que é o eixo em torno do qual se organiza a personalidade humana, poderá fazer eleitores, não terá feito cidadãos. (CAMPOS, 1930, p. 101; 102).

Campos sugere que a qualidade da educação escolar era mais importante que sua difusão; isto é, que a quantidade de escolas. Essa possibilidade contradiz, porém, o discurso de seu governo vai contra a multiplicação de escolas propalada nos "Discursos presidenciais do Estado de Minas Gerais", como se lê nesta passagem:

Convergi para a educação publica toda a minha attenção. Fiz della a preoccupação dominante de meu governo. Concentrei nella o melhor dos meus esforços. Reformei o ensino normal e primário. Fundei dezenove escolas normaes e refundi, de todo em todo, as duas únicas escolas normaes officiais existentes. Creei e installei 3.662 escolas primarias, o que quer dizer que foram multiplicadas por três as escolas que encontrei. Fundei e installei quatro gymnasios. (CAMPOS, 1930, p. 236).

Dito isso, não podemos negar que o discurso de Campos relativo à renovação educacional em Minas Gerais não convergisse para modernização do estado. Mas essa convergência não ficou isenta das contradições que marcaram o processo modernizador em Minas Gerais e no Brasil. Os exemplos de seu discurso permitem afirmar essa contradição. Ora, embora insistisse na qualidade da educação, o governo Antônio Carlos enfatizou o dado quantitativo: apresentou a quantidade não só em números exatos — $3.662-$, mas 
também em proporções - três vezes mais. Além disso, a concepção de educação, de criança e dos fins da escola sugere que ele contribuiu para manter a estrutura social vigente: excludente. Ora, Campos via a educação escolar como instrumento de conservação num momento em que a ideia de modernização supunha quebra do conservadorismo, abertura ao novo, ruptura com a tradição "reinante"; logo, não cabia falar na formação de cidadãos transformadores (modernizadores) porque a sociedade deveria permanecer como estava. Mais que isso, na escola segundo Campos, a liberdade, espontaneidade e naturalidade da criança é cerceada pela assimilação adaptativa e disciplinada de um estado de coisas. Assim, se Campos almejava à modernidade mineira, não ficou ileso aos entraves à modernização uniforme e incisiva de Minas Gerais; a faceta pró-modernização de seu discurso mostra vínculos com a estrutura oligárquica — mais conservadora, mais arcaica.

Até 1920, diz Wirth (1982), Minas Gerais tinha liderança econômica, demográfica e política, segundo - depois foi superado pelo estado de São Paulo demograficamente, cuja economia diversificada prometia oportunidades variadas, diferentemente da economia conservadora mineira, de estabilidade social forte. Como o estado padecia de doenças epidêmicas em algumas localidades, supõe-se que a saúde pública fosse precária; assim como a educação - a taxa de analfabetismo era alta. Esses fatores, por si só, diziam muito da falta de progresso e modernização e estimularam a migração.

Ainda na visão de Wirth, numa economia de base agrícola (o café) e pastoril (a pecuária de leite), a industrialização engatinhava: atendia o mercado doméstico e empregava pouca gente. A isso se aliam uma produção cafeeira irregular e um sistema viário e transporte deficiente, que reforçava a dependência de São Paulo e do Rio Grande do Sul, estados com os quais Minas Gerais tinha relações econômicas de dependência. Assim, resolver os problemas supunha construir estradas de ferro e estimular o mercado interno, para anular a dependência. Todavia, mesmo a construção de ferrovias e abertura de rodovias entre 1870 e 1930 não integraram suficientemente as regiões do estado, logo estimularam o fortalecimento do mercado interno, segundo diz Wirth (1982).

Com efeito, a fraqueza e desorganização do mercado mineiro compuseram a formulação de projetos políticos à época, pois foram associadas com o analfabetismo. Assim, a reforma educacional de Antônio Carlos e Francisco Campos tinha respaldo não só em argumentos do contexto nacional, mas também em necessidades criadas, sobretudo, pela elite mineira por trás de um programa de governo para acelerar o desenvolvimento e a modernização do estado. Uma vez eleitos, esses dois políticos vazaram essas necessidades em linguagem oficial, sobretudo as educacionais: o assunto educação foi patente nos discursos presidenciais de Antônio Carlos em 1927/28/29/30.

Como tentamos contextualizar até aqui, a educação foi tomada como indício de modernização de Minas Gerais. Mas assunção das questões educacionais como programa político tinha, segundo Dahlberg, Moss e Pence (2003) e num contexto maior, outros interesses que não o educar o povo propriamente dito. Ora, na proporção que a economia capitalista assumia as rédeas do desenvolvimento, políticos e líderes empresariais pouco afeitos à educação passaram a expressar preocupação e disposição para agir em prol dessa faceta da sociedade. A defesa da qualidade e da difusão da instrução primária seguiu a lógica da relação custo-benefício: formar e manter uma força de trabalho estável e qualificada para o futuro: a industrialização.

Isso sugere que esse interesse pela educação se voltava à instrução da população urbana. Do contrário, o projeto político de Antônio Carlos teria previsto uma reforma que mudasse, também, a feição da educação rural em Minas Gerais. A reforma propôs uma modificação no ensino rural: "Até á reforma, o curso nas escolas ruraes era apenas de dois 
annos. [...] [Após a reforma] o curso nas escolas ruraes passou a ser de tres annos, o que, certamente, contribuirá para melhorar o ensino" (MINAS GERAIS, 1928, s. p.). Pode-se aventar a possibilidade de que esse "desdém" pelo ensino no campo se explique pela ideia - construída e apropriada pela sociedade - de que o meio rural é atrasado e tradicional; isto é, antítese da vida urbana, da vida moderna, do progresso (PAIM, 1984; ORTIZ, 2001). Nessa ótica, ao ser associada com a educação que deveria democratizar o país, a modernização de Minas Gerais ajudou a esconder problemas mais graves de uma sociedade cuja população era, a maioria, habitante do campo.

A ênfase na educação primária não anulou interesse de Antônio Carlos e Francisco Campos por outros níveis educacionais como o ensino superior, embora investimento tenha sido quase imperceptível. Segundo Nagle (2001), a "elite nacional" pedia uma formação superior, por isso era necessário agradá-la; isto é, estruturar uma universidade que pudesse formar uma elite de cultura e ciência apta a governar o país. Atentos a essa demanda elitista, Campos e Andrada criaram a Universidade de Minas Gerais, ${ }^{14}$ cuja sede seria o prédio da Faculdade de Direito, influente ${ }^{15}$ na formação da intelectualidade e da política mineiras. Assim, criar uma universidade cumpria parte de um programa político coerente com os interesses das oligarquias: além de escolas normais (e secundárias) para alimentar os valores humanistas ocidentais, havia escolas superiores para elite; para massa, a escola primária, como forma de suprir uma demanda social que poderia garantir não só votos, mas também eleitorado fiel.

A permanência no poder supunha outras condições, a exemplo de laços que deviam ser firmados com grupos sociais distintos, úteis à influência do governo de Antônio Carlos. Dentre esses grupos está o professorado, convocado a participar do Congresso de Ensino Primário $^{16}$ para conhecer as ideias educacionais e, uma vez cientes destas, ser cooptado a defender o projeto político-educacional modernizante do governo Antônio Carlos. Assim, Antônio Carlos e Francisco Campos divulgaram seu projeto político com apoio da "densa e compacta massa de analphabetos" e do professorado, tido como central à concretização da reforma educacional.

\section{Considerações finais}

Esta leitura analítica dos discursos de Antônio Carlos e Francisco Campos tentou mostrar os vínculos desses dois políticos e de seu programa de governo como o projeto de modernização de Minas Gerais pela via da educação. Essa possibilidade compunha o ideário nacional de modernização da sociedade, mas tinha algo de utópico, visto que educar o povo tinha profundo de fazer a massa aderir - sobretudo pelo voto - ao regime republicano e o que ele trazia a reboque: industrialização, controle social e democracia, dentre outros pontos.

Esse discurso educacional modernizante na década de 1920 foi uma forma de projetar Francisco Campos e Antônio Carlos na elite política nacional. Seu projeto político desenvolvido e a dimensão alcançada pela reforma educacional os alçaram à condição de homens prestigiados na intelectualidade e elite dirigente, nas quais ocuparam posições de destaque, a exemplo de Campos, que se tornou ministro da Educação. Mas, se a elaboração interna coerente de sua proposta política garantiu futuro para suas ideias no cenário nacional, isso não bastou para concretizar o projeto de modernização e democratização no estado em seu conjunto. Os entraves à modernização de Minas Gerais como processo político advinham justamente das formações oligárquicas que sustentavam o programa do governo Antônio Carlos, para as quais modernização significava democratizar — assegurar o direito de voto e angariar eleitores — para proteger seus bens e aumentá-los. 


\section{Bibliografia}

ABREU, Alzira Alves de et al. (Coord.). Dicionário histórico-biográfico brasileiro pós1930. Rio de Janeiro: ed. fgv; cpdoc, 2001. 5v., p. 999.

BOBBIO, Norberto. Dicionário de política. Brasília: ed. unb; Linha Gráfica, 1991.

BRASIL. Constituição (1891). Constituição da República dos Estados Unidos do Brasil: promulgada em 24 de fevereiro de 1891. Rio de Janeiro: Sala das Sessões do Congresso Nacional Constituinte, 1891.

CAMPOS, Francisco Luis da Silva. Pela civilização mineira. Belo Horizonte: Imprensa Oficial, 1930.

CARVALHO, Marta Maria Chagas de. Molde nacional e fôrma cívica: higiene, moral e trabalho no projeto da Associação Brasileira de Educação. Bragança Paulista: ed. usf, 1998.

CURY, Carlos Roberto Jamil. A educação e a primeira constituinte republicana. In: fávero, Osmar (Org.). A educação nas constituintes brasileiras 1823-1988. 2. ed. Campinas: Autores Associados, 2001a.

CURY, Carlos Roberto Jamil. Cidadania republicana e educação: governo provisório do mal. Deodoro e Congresso constituinte de 1890-1891. Rio de Janeiro: dp\&a, 2001b.

CURY, Carlos Roberto Jamil. Ensino religioso. Relato histórico de uma polêmica. In: carvalho, Carlos Henrique de; gonçalves neto, Wenceslau (Org.). Estado, igreja e educação: o mundo ibero-americano nos séculos xix e xx. Campinas: Alínea, 2010.

CURY, Carlos Roberto Jamil. Projetos republicanos e a questão da educação nacional. In: vago, Tarcísio Mauro et al. (Org.). Intelectuais e escola pública no Brasil: séculos xix e xx. Belo Horizonte: Mazza, 2009.

DAHLBERG, Gunilla; moss, Peter; pence. Alan. Qualidade na educação infantil da primeira infância: perspectivas pós-modernas. Porto Alegre: Artmed, 2003.

Fundação Getulio Vargas/FGV. Francisco Campos. Disponível em:

$\langle$ http://cpdoc.fgv.br/producao/dossies/fatosimagem/biografias/francisco_campos $>$. Acesso em: 6 set. 2009.

Instituto Brasileiro de Georgrafia e Estatistica/Ibge. Tendências demográficas: uma análise dos resultados do universo do censo demográfico de 2000. Rio de Janeiro: ibge, 2002.

MINAS GERAIS. Constituição (1891). Constituição do Estado Federado de Minas Gerais: promulgada em 15 de junho de 1891. Ouro Preto: Sala das Sessões do Congresso Constituinte Mineiro, 1891.

MINAS GERAIS. Decreto 7.970. Regulamento do Ensino Primário de Minas Gerais: promulgado em 15 de outubro de 1927. Uberaba: Palácio da Presidência do Estado de Minas Gerais, 1927a. 
MINAS GERAIS. Mensagem presidencial do presidente Antônio Carlos Ribeiro de Andrada dirigida ao Plenário em 1927b. In: arquivo público mineiro/apm. Relatórios de mensagens do governo mineiro - mensagens presidenciais de Antônio Carlos Ribeiro de Andrada. Filme 5 e 6, gaveta B1.

MINAS GERAIS. Mensagem presidencial do presidente Antônio Carlos Ribeiro de Andrada dirigida ao Plenário em 1928. In: arquivo público mineiro/apm. Relatórios de mensagens DO GOVERNO MINEIRO - mensagens presidenciais de Antônio Carlos Ribeiro de Andrada. Filme 5 e 6, gaveta B1.

MINAS GERAIS. Mensagem presidencial do presidente Antônio Carlos Ribeiro de Andrada dirigida ao Plenário em 1930. In: arquivo público mineiro/apm. Relatórios de mensagens do governo mineiro - mensagens presidenciais de Antônio Carlos Ribeiro de Andrada. Filme 5 e 6, gaveta B1.

NAGLE, Jorge. Educação e sociedade na Primeira República. 2. ed. Rio de Janeiro: dp\&a, 2001.

OLIVEIRA, Itamar de. Francisco Campos: a inteligência no poder. Recife: Libertas, 1996.

ORTIZ, Renato. Cultura brasileira e identidade nacional. São Paulo: Brasiliense, 2003.

PAIM, Antônio. História das idéias filosóficas no Brasil. 3. ed. São Paulo: Convívio; Brasília]: inl, Fundação Nacional Pró-memória, 1984.

PAIM, Antonio. História do liberalismo brasileiro. São Paulo: Mandarim, 1998.

PAIM, Antonio. O liberalismo contemporâneo. Rio de Janeiro: Tempo Brasileiro, 2000.

PAULA, João Antonio de. Raízes da modernidade em Minas Gerais. Belo Horizonte: Autêntica, 2000.

PÉCAUT, Daniel. Os intelectuais e a política no Brasil: entre o povo e a nação. São Paulo: Ática, 1990.

PEIXOTO, Anamaria Casasanta. Educação no Brasil — anos vinte. São Paulo: Loyola, 1983.

PEREIRA, Lígia Maria Leite; faria, Maria Auxiliadora de. Presidente Antônio Carlos: um Andrada da República: o arquiteto da revolução de 30. Rio de Janeiro: Nova Fronteira, 1998.

PINHEIRO, Paulo Sérgio. Classes médias urbanas: Formação, natureza, intervenção na vida política. In: O Brasil republicano; tomo iii: sociedade e instituições (18891930). Rio de Janeiro: Bertrand Brasil, 1997.

RODRIGUES, Almerinda M. R. V. O movimento da Escola Nova no sul de Mato Grosso: uma análise de suas contribuições para a educação do Estado na primeira metade do século xx. Dissertação (Mestrado em História) - Universidade Federal do Mato Grosso do Sul, Dourados, 2006. 
VEIGA, Cynthia Greive. História da educação. São Paulo: Ática, 2007.

VIDAL, Diana Gonçalves (Org.). Grupos escolares: cultura escolar primária e escolarização da infância no Brasil (1893-1971). Campinas, Mercado de Letras, 2006.

VIDAL, Diana Gonçalves. Modernismos, modernidades e educação: o lugar dos intelectuais no Brasil dos anos 1930. In: vago, Tarcísio Mauro et al. (Org.). Intelectuais e escola pública no Brasil: séculos xix e xx. Belo Horizonte: Mazza, 2009.

WEFFORT, Francisco C. (Org.). Os clássicos da política. 12. ed. São Paulo: Ática, 2006.

WIRTH, John D. O fiel da balança: Minas Gerais na federação brasileira. Rio de Janeiro: Paz e Terra, 1982.

Recebido em janeiro-13

Aprovado em maio-13

\section{Notas}

${ }^{1}$ Doutor em História pela Universidade de São Paulo. Professor da Faculdade de Educação e do Programa de
Pós-Graduação em Educação da Universidade Federal de Uberlândia.
${ }^{2}$ Doutora em Educação pela Universidade de Campinas (UNICAMP). Professora do Programa de Pós-
Graduação em Educação da Universidade de Uberaba (UNIUBE). E-mail: lucianabeatrizcarvalho@yahoo.com.br

3 “Art. 70 - São eleitores os cidadãos maiores de 21 anos que se alistarem na forma da lei. $\S 1^{\text {o }}$ - Não podem alistar-se eleitores para as eleições federais ou para as dos Estados: $1^{\circ}$ ) os mendigos; $2^{\circ}$ ) os analfabetos; $3^{\circ}$ ) as praças de pré, excetuados os alunos das escolas militares de ensino superior; $4^{\circ}$ ) os religiosos de ordens monásticas, companhias, congregações ou comunidades de qualquer denominação, sujeitas a voto de obediência, regra ou estatuto que importe a renúncia da liberdade Individual” (BRASIL, 1891).

${ }^{4}$ Cf. PÉCAUT, 1990.

${ }^{5}$ Criou o sistema de grupos escolares; reformulou os níveis primário, normal e superior; começou a pensar na criação de "escola normal modelo"; aprovou o regimento interno dos grupos escolares e reforçou a fiscalização; prescreveu os métodos intuitivo e prático, dentre outras ações. Contudo, não inovou no ensino normal, que continuou a ser simples e resumido.

${ }^{6}$ Aprovou o regulamento da reorganização escolar, na qual uma mudança-chave ocorreu na duração do curso normal (de três anos para quatro), além de classificar a escola normal de Belo Horizonte como modelo.

${ }^{7}$ Pouco distinta da reforma João Pinheiro, determinou normas ao pré-primário, primário e normal, criou escolas rurais, previu escolas dominicais, fixou diretrizes para exercícios físicos e, sobretudo, estabeleceu a primeira escola infantil.

${ }^{8}$ Sem fazer mudanças fundamentais, fixou instruções ao ensino da escola infantil.

${ }^{9}$ Estipulou gratificação especial a docentes normalistas, alinhou muitas escolas normais à Escola Normal Modelo e criou numerosos grupos escolares; também aprovou o Regulamento do Ensino nas Escolas Normais e programas de ensino para o jardim de infância e para cursos complementares, primários agrícolas e ensino primário.

10 Governador, Artur Bernardes; secretário do Interior, Afonso Pena Júnior. Como mudanças mais importantes, essa reforma criou escolas rurais, nomeou professores de ensino primário e facultou o ensino da religião católica; os quesitos organização, metodologia e programas não foram revistos, embora tenha atido ao ensino universitário com a criação da Escola Superior de Agricultura e Veterinária.

11 Natural de Barbacena (MG), estudou segundo métodos pedagógicos contrários ao castigo físico e favoráveis à persuasão e ao apelo à dignidade como atitudes mais aptas à formação de cidadãos dignos. Na faculdade de Direito de São Paulo, deu vazão à vocação e ao desejo de participar da vida política, entusisamdno pela causa republicana e pelo liberalismo clássico. Sua preocupação com o ensino escolar foi 
tal que a educação se tornou um compromisso expressivo de sua plataforma de governo. Ciente da situação precária da educação, ao assumir a presidência de Minas focou na melhoria dos níveis primário e normal, sobretudo. Também reiterava o pressuposto de que o aprimoramento do ensino primário era condição direta para o progresso social e econômico.

${ }^{12}$ Francisco Campos é natural de Dores do Indaiá (MG), cidade que, segundo Oliveira (1996), influenciou sua formação pessoal, intelectual e política. Sua infância ocorreu no momento em que políticos locais levaram a efeito iniciativas que pudessem fazer a cidade progredir. A população local tinha entusiasmo pelas artes e havia um panorama cultural promissor: teatro, jornais e biblioteca com acervo diverso já em 1903. Essa tendência se refletia na educação, cuja qualidade preocupava as autoridades, pois elas a viam como indício de progresso - coerentemente com o ideal republicano de então. Após iniciar seus estudos nesse ambiente, Campos foi, em 1910, estudar Direito na Faculdade Livre de Direito. Academia de ciências políticas, jurídicas, econômicas e administrativas de grande projeção, essa faculdade ofereceu a Campos um ambiente que influenciou sua formação política e estimulou sua produção intelectual, que lhe deu projeção pessoal e abriu perspectivas na carreira política. Uma vez advogado e jurista de formação, Campos se elegeu deputado estadual, em 1919, pelo Partido Republicano Mineiro (PRM). Em 1926, assumiu a Secretaria do Interior de Minas Gerais, na qual deu muita atenção à inspetoria da instrução; seu papel na política educacional do governo Antônio Carlos sugere isso.

${ }^{13}$ A escola nova tem no pensamento de John Dewey uma de suas bases centrais. No dizer de Veiga (2007), Dewey espera, dentre outras coisas, que a escola seja capaz de estimular o desenvolvimento dos interesses fundamentais da criança: comunicação verbal, descoberta, capacidade de construir objetos etc. O espaço escolar seria, então, uma "comunidade em miniatura" capaz de estimular e facilitar vivências produtivas laboratoriais e em oficinas, por exemplo, assim como os jogos (VEIGA, 2007, p. 227).

14 “A lei n. 956, de 7 de setembro de 1927, creou a Universidade de Minas Geraes. A mesma lei auctorizou o Governo a constituir patrimonios, cujos rendimentos, respectivamente, de 200:000\$000, 350:000\$, 600:000\$000 e 50:000\$000, auxiliem a manutenção da Faculdade de Direito, da Escola de Engenharia, da Faculdade de Medicina e da Faculdade de Odontologia e Pharmacia de Bello Horizonte, que se reuniram para constituir a Universidade de Minas Geraes. O decreto n. 7.921, de 22 de setembro do mesmo anno, approvou o Regulamento da Universidade, que, considerada fundação, com personalidade jurídica de direito privado, objectiva o desenvolvimento dos institutos que lhe são incorporados, o estímulo da cultura scientífica, o aperfeiçoamento do ensino e, em summa, o engrandecimento intellectual e moral do Estado de Minas e do Brasil.” (MINAS GERAIS, 1928).

15 No dizer de Wirth (1982, p. 139): “Os professores passavam facilmente para cargos políticos e administrativos importantes e os alunos tinham esperanças de subir rapidamente, uma vez de posse de seus certificados de bacharéis e doutores. [...] A classe media via nos diplomas a marca de um homem instruído. [...] O acesso aos corredores do poder era muito mais fácil para aquele que portava o anel de rubi do advogado e reforçado pelo companheirismo dos colegas de mesmo status."

16 "Atendendo a convocação do governo, reuniu-se, nesta Capital, em maio próximo findo, o Congresso de Ensino Primário, cujas luzes, devendo provir de pessoal experimentado, pareceram úteis à administração, para o fim da reforma que planejo, e já exposta, em linhas gerais, por mim e pelo Secretário do Interior, em vários documentos públicos. As resoluções do congresso, em sua maioria merecedoras de acatamento, terão o devido apreço na elaboração do regulamento que, sobre esse importante assunto, será, dentro em pouco, expedido.” (MINAS GERAIS, 1927b). 